\title{
Comparison of ketamine-dexmedetomidine-methadone and tiletamine-zolazepam-methadone combinations for short-term anaesthesia in domestic pigs
}

\author{
V. De Monte ${ }^{\text {a,*, }}$, F. Staffieri ${ }^{\text {b}}$, A. Di Meo ${ }^{\text {a }}$, J. Vannucci ${ }^{\text {c }}$, A. Bufalari ${ }^{\text {a }}$ \\ a Department of Veterinary Medicine, University of Perugia, via San Costanzo 4, 06126 Perugia, Italy \\ ${ }^{\mathrm{b}}$ Department of Emergencies and Organ Transplantation, Section of Veterinary Clinics and Animal Production, University of Bari, Str per Casamassima \\ km3, 70010 Bari, Italy \\ ${ }^{c}$ Thoracic Surgery Unit, Ospedale Santa Maria della Misericordia Loc. S. Andrea Fratte, 06134, Perugia, Italy
}

\section{A R T I C L E I N F}

\section{Article history:}

Accepted 17 May 2015

\section{Keywords:}

Pig

Anaesthesia

Ketamine

Tiletamine

Oxygenation index

\begin{abstract}
A B S T R A C T
Cardiorespiratory effects, quality of induction, depth of anaesthesia and quality of recovery were compared in pigs anaesthetised with $8 \mathrm{mg} / \mathrm{kg}$ ketamine, $20 \mu \mathrm{g} / \mathrm{kg}$ dexmedetomidine and $0.2 \mathrm{mg} / \mathrm{kg}$ methadone (KDM, $n=18$ ) or $8 \mathrm{mg} / \mathrm{kg}$ tiletamine-zolazepam and $0.2 \mathrm{mg} / \mathrm{kg}$ methadone (TZM, $n=9$ ). Anaesthesia with KDM was partially reversed in nine animals with $0.2 \mathrm{mg} / \mathrm{kg}$ atipamezole (KDMat). Sedation was observed earlier in the TZM group $(47.2 \pm 25.3 \mathrm{~s})$ than the KDM group $(91.5 \pm 37.4 \mathrm{~s})$. Sternal and lateral recumbency were achieved earlier in the TZM group ( $76.3 \pm 36.5 \mathrm{~s}$ and $132.1 \pm 30.5 \mathrm{~s}$, respectively) than in the KDM group $\left(149.1 \pm 58.7 \mathrm{~s}\right.$ and $249.2 \pm 84.0 \mathrm{~s}$, respectively). $\mathrm{PaO}_{2}, \mathrm{SaO}_{2}$ and $\mathrm{PaO}_{2}:$ FiO $\mathrm{O}_{2}$ were lower in the TZM group $(68.7 \pm 4.1 \mathrm{mmHg}, 93.4 \pm 1.4 \%$ and $327.2 \pm 19.9 \mathrm{mmHg}$, respectively) than in the KDM group $\left(80.4 \pm 5.9 \mathrm{mmHg}, 95.7 \pm 1.0 \%\right.$ and $380.4 \pm 25.6 \mathrm{mmHg}$, respectively). Fshunt and $\mathrm{P}_{(\mathrm{A}-\mathrm{a})} \mathrm{O}_{2}$ were higher in the TZM group $(24.0 \pm 11.8 \%$ and $31.4 \pm 3.8 \mathrm{mmHg}$, respectively) than in the KDM group (13.4 $\pm 3.2 \%$ and $20.7 \pm 7.4 \mathrm{mmHg}$, respectively). Times from drug injection to first head movements, sternal recumbency and standing/walking were significantly shorter in the KDM group $(45.1 \pm 10.5,48.4 \pm 12.6$ and $54.4 \pm 17.8 \mathrm{~min}$, respectively) than in the TZM group $(57.8 \pm 11.4,93.1 \pm 14.2$ and $165.7 \pm 56.6 \mathrm{~min}$, respectively). The median recovery score was higher in the TZM group than in the KDMnoat and KDMat subgroups. Both drug combinations provided adequate anaesthesia for minor procedures lasting about $30 \mathrm{~min}$, but TZM was associated with a poor recovery and oxygenation.
\end{abstract}

(c) 2015 Elsevier Ltd. All rights reserved.

\section{Introduction}

Short-term anaesthesia of domestic pigs is often required in biomedical research for minor surgical or diagnostic procedures (Hastings et al., 1982; Swindle et al., 1994; Nunes et al., 2007; Grasso et al., 2009; Staffieri et al., 2012; Jordan et al., 2014). The ideal anaesthetic protocol in pigs should provide fast and reliable immobilisation, minimal cardiovascular and respiratory depression, and adequate analgesia and muscle relaxation.

Pigs are difficult to handle and restrain due to their temperament and resistance to sedative drug combinations (Brodbelt and Taylor, 1999; Heinonen et al., 2009; Lee et al., 2010; Linkenhoker et al., 2010). Restraint for IM administration of drugs seems to be less stressful than for intravenous (IV) injection (Henrikson et al., 1995). The combination of two or more drugs (balanced anaesthesia) targeting specific clinical effects (hypnosis, analgesia and muscle

\footnotetext{
* Corresponding author. Tel.: +39 3476690137.

E-mail address: valedemo@inwind.it (V. De Monte).
}

relaxation) represents the current best standard for injectable IM anaesthesia in pigs in terms of safety and efficacy (Nishimura et al., 1992).

Cyclohexane anaesthetic drugs (ketamine and tiletamine) are commonly used for sedation and anaesthesia in pigs, since they produce rapid and reliable immobilisation after IM administration, with a high margin of safety and few cardiopulmonary side effects (Lin et al., 1993; Boschert et al., 1996). These drugs produce a state of dissociative anaesthesia resulting from an electrophysiological dissociation between the limbic and cortical system, do not usually depress the cardiovascular or respiratory systems and have significant analgesic effects (Reves et al., 2005; Craven, 2007). Tiletamine is more potent than ketamine and is commercially available in combination with the benzodiazepine tranquiliser zolazepam (Telazol) in a 1:1 combination. The major collateral effects of dissociative drugs are muscle rigidity, ataxia and excitatory effects during recovery (Lin et al., 1993). To counteract these side effects, $\alpha 2$ agonists (xylazine, detomidine and medetomidine) and opioids (butorphanol and buprenorphine) are commonly combined with dissociative drugs for short-term anaesthesia in pigs (Nishimura et al., 
1992; Sakaguchi et al., 1992, 1995, 1996; Brodbelt and Taylor, 1999; Heinonen et al., 2009; Lee and Kim, 2012; Santos González et al., 2013). However, there are few reports of the use of dexmedetomidine and methadone in this species (Hermansen et al., 1986; Sano et al., 2010; Santos et al., 2015).

Dexmedetomidine is the latest $\alpha 2$ adrenoceptor agonist available for veterinary use; it is an enantiomer of medetomidine and provides sedative and analgesic effects (Pypendop et al., 2011). $\alpha 2$ agonists exert their sedative effects through stimulation of $\alpha 2$ adrenoceptors in the brain, decreasing release of noradrenaline (norepinephrine). Sedation results from decreased activity of ascending neural projections to the cerebral cortex and limbic system (Stenberg, 1986). Analgesia appears to be the result of both cerebral and spinal effects, possibly in part mediated by serotonin and the descending endogenous analgesia system (Sinclair, 2003).

Methadone is a synthetic $\mu$ opioid agonist with potent and short acting (about $4 \mathrm{~h}$ ) analgesic and sedative effects (Lamont and Mathews, 2007). Methadone has pharmacological properties qualitatively similar to those of morphine, the prototypical opioid analgesic, but possessing additional antagonistic affinity for $\mathrm{N}$-methyl-D-aspartate (NMDA) receptors, thus contributing to analgesia by minimising central nervous system sensitisation (Ebert et al., 1995).

Considering the unique and advantageous characteristics of dexmedetomidine and methadone, the aim of this study was to evaluate the physiological effects of an anaesthesia protocol that includes these drugs in comparison with a traditional protocol to produce short-term anaesthesia in pigs undergoing skin and mucosal biopsies. Ketamine-dexmedetomidine-methadone and tiletamine-zolazepammethadone combinations were evaluated in terms of quality of induction, depth of anaesthesia, quality of recovery, and cardiovascular and respiratory effects. The study did not consider situations in which pigs are intended for food production, since only ketamine is licensed for food producing animals among the drugs tested. ${ }^{1}$

\section{Materials and methods}

Animals

Twenty-seven Landrace $\times$ Large white pigs ( 22 female, 5 male) were used in this study. Food was withheld for $24 \mathrm{~h}$ and water was withheld for $2 \mathrm{~h}$ before the administration of drugs to prevent any possible adverse effects, such as vomiting during the anaesthetic or recovery periods. The study protocol was approved by the Ethics Committee of the University of Perugia (approval number 2013-027R; date of approval 6 September 2013). Pigs were involved in another experimental study in which four skin biopsies (dorsal thoracic area) and two mucosal biopsies (ventral aspect of the tongue) were collected with a cutaneous punch $(0.6 \mathrm{~mm}$ diameter) under general anaesthesia. The aim of the surgical study was to compare the quality of incisions and degree of thermal injury produced by different surgical instruments and their effects on reepithelialisation. The number and allocation of the pigs among groups were based on the main surgical experimental study. Physical examination carried out the day before the experiment, including measurement of rectal temperature $\left(\mathrm{T},{ }^{\circ} \mathrm{C}\right)$, heart rate (HR, beats/min) and respiratory rate (RR, breaths/min), had shown the pigs were healthy. The experiments were carried out at room temperature $\left(18-20^{\circ} \mathrm{C}\right)$. The mean body weights (TZM $41.0 \pm 6.1 \mathrm{~kg}$; KDM $40.5 \pm 6.6 \mathrm{~kg}$ ) and ages (TZM $86.6 \pm 7.4$ days; KDM $85.2 \pm 6.6$ days) were similar in both groups.

\section{Study design}

Eighteen animals (KDM group) were anaesthetised IM with a combination of ketamine ( $8 \mathrm{mg} / \mathrm{kg}$; Ketavet $100,100 \mathrm{mg} / \mathrm{mL}$, Intervet), dexmedetomidine ( $20 \mu \mathrm{g} / \mathrm{kg}$; Dexdomitor, $0.5 \mathrm{mg} / \mathrm{mL}$, Elanco Animal Health) and methadone $(0.2 \mathrm{mg} / \mathrm{kg}$; Eptadone, $10 \mathrm{mg} / \mathrm{mL}$, Molteni Farmaceutici). Nine animals (TZM group) received a combination of tiletamine-zolazepam ( $8 \mathrm{mg} / \mathrm{kg}$; Zoletil $100,100 \mathrm{mg} / \mathrm{mL}$, Virbac) and methadone $(0.2 \mathrm{mg} / \mathrm{kg})$ IM. Pigs in the KDM group were further divided in two subgroups of nine animals each based on the administration (KDMat) or not (KDMnoat) of atipamezole $(0.2 \mathrm{mg} / \mathrm{kg}$; Antisedan, $5 \mathrm{mg} / \mathrm{mL}$, Elanco Animal Health) during recovery. All animals were injected into the neck muscles caudal to the base of the

\footnotetext{
1 See: http://ec.europa.eu/health/files/eudralex/vol-5/reg_2010_37/reg_2010 37 en.pdf (accessed 28 December 2014).
}

ear (splenius and brachiocephalic muscles). Randomisation of pigs among treatment groups was performed using Research Randomizer. ${ }^{2}$

The times from injection of drugs to the first signs of sedation, and to sternal and lateral recumbency, were recorded. The quality of induction was assessed using a descriptive score ranging from 1 (excellent) to 4 (poor; see Appendix: Supplementary Table S1). Ten minutes after administration of drugs, pigs with inadequate induction (scores 3-4; one pig in the KDM group) received an additional dose of ketamine ( $1 \mathrm{mg} / \mathrm{kg}$, IV; KDM group) or tiletamine-zolazepam ( $1 \mathrm{mg} / \mathrm{kg}$, IV; TZM group); these animals were excluded from the study. When the induction was adequate (scores $1-2$ ), pigs were approached, blindfolded and placed in left lateral recumbency; animals were not intubated and breathed room air (fraction of inspired oxygen, $\mathrm{FiO}_{2}$ 0.21)

Depth of anaesthesia (anaesthesia score) (Laricchiuta et al., 2012) was assessed by checking palpebral, pedal, auricular and anal reflexes, jaw tone, presence of voluntary movements and reaction to painful stimuli (blood sampling, ear notching), scored from 1 (deep anaesthesia) to 6 (very light sedation; see Appendix: Supplementary Table S2). If the anaesthesia score was 5-6 (one pig in TZM group), pigs received an additional dose of ketamine ( $1 \mathrm{mg} / \mathrm{kg}$, IV; KDM group) or tiletaminezolazepam ( $1 \mathrm{mg} / \mathrm{kg}$, IV; TZM group) and these animals were excluded from the study.

\section{Monitoring and data collection}

Heart rate, $\mathrm{RR}, \mathrm{T}$, oxygen haemoglobin saturation $\left(\mathrm{SpO}_{2}, \%\right)$, non-invasive systolic, diastolic and mean arterial pressures (SAP, DAP, MAP, respectively, mmHg; HB100 multiparametric monitor, Foschi) and depth of anaesthesia were recorded at the time of the first approach (T0) and after 10 (T10), 20 (T20) and 30 (T30) min. Skin and tongue biopsies were collected between T10 and T30; no other surgical interventions were performed. An arterial (femoral artery) blood sample was collected at T20 (3 mL BD Preset syringe, BD). Arterial samples were analysed immediately using a portable blood gas analyser (i-STAT Portable Clinical Analyzer, Abbott). The measured and calculated parameters were $\mathrm{pH}$, partial arterial pressure of carbon dioxide $\left(\mathrm{PaCO}_{2}, \mathrm{mmHg}\right)$, partial arterial pressure of oxygen $\left(\mathrm{PaO}_{2}, \mathrm{mmHg}\right)$, base excess (BE, mmol/L), haematocrit (Hct, \%), bicarbonate concentration $\left(\mathrm{HCO}_{3}{ }^{-}, \mathrm{mmol} / \mathrm{L}\right)$, haemoglobin concentration ( $\mathrm{tHb}, \mathrm{g} / \mathrm{dL})$, oxygen haemoglobin saturation $\left(\mathrm{SaO}_{2}, \%\right)$, concentrations of $\mathrm{Na}^{+}, \mathrm{K}^{+}$and $\mathrm{Ca}^{2+}(\mathrm{mmol} / \mathrm{L})$, arterial $\mathrm{CO}_{2}\left(\mathrm{TCO}_{2}, \mathrm{vol} \%\right)$, and concentration of glucose $(\mathrm{mg} / \mathrm{dL})$. The alveolar to arterial oxygen gradient $\left[\mathrm{P}(\mathrm{A-a}) \mathrm{O}_{2}\right], \mathrm{PaO}_{2}: \mathrm{FiO}_{2}$ ratio $(\mathrm{mmHg})$ and estimated shunt fraction (Fshunt,\%) were calculated (Araos et al., 2012). All parameters were corrected for the rectal temperature measured at the time of sampling.

The $\mathrm{P}_{(\mathrm{A}-\mathrm{a})} \mathrm{O}_{2}$ was calculated as:

$\mathrm{P}_{(\mathrm{A}-\mathrm{a})} \mathrm{O}_{2}=\left(\left[\mathrm{P}_{\mathrm{B}}-\mathrm{PH}_{2} \mathrm{O}\right] \times \mathrm{FiO}_{2}-\mathrm{PaCO}_{2} / \mathrm{R}\right)-\mathrm{PaO}_{2}$

where $\mathrm{P}_{\mathrm{B}}$ is the barometric pressure, $\mathrm{PH}_{2} \mathrm{O}$ is the water vapour pressure, $\mathrm{FiO}_{2}$ is the inspired oxygen fraction and $\mathrm{R}$ is the respiratory exchange ratio, assumed to be 0.9 (Cohen et al., 1995). The $\mathrm{PH}_{2} \mathrm{O}$ was corrected for the rectal temperature recorded at the time of arterial blood collection (Mackenzie, 1963).

The Fshunt was calculated as:

Fshunt: $\left(\left[\mathrm{Cc}^{\prime} \mathrm{O}_{2}-\mathrm{CaO}_{2}\right] /\left[\mathrm{Cc}^{\prime} \mathrm{O}_{2}-\mathrm{CaO}_{2}+3.5 \mathrm{~mL} / \mathrm{dL}\right]\right) \times 100$

where $\mathrm{Cc}^{\prime} \mathrm{O}_{2}$ is the pulmonary end-capillary oxygen content, $\mathrm{CaO}_{2}$ is the arterial oxygen content and $3.5 \mathrm{~mL} / \mathrm{dL}$ is an approximate fixed value of the arterial-to-mixed venous oxygen content difference.

The $\mathrm{Cc}^{\prime} \mathrm{O}_{2}$ and $\mathrm{CaO}_{2}$ were calculated as follows:

$\mathrm{Cc}^{\prime} \mathrm{O}_{2}=\mathrm{Hb} \times 1.31 \times \mathrm{Sc}^{\prime} \mathrm{O}_{2}+0.0031 \times \mathrm{Pc}^{\prime} \mathrm{O}_{2}$

$\mathrm{CaO}_{2}=\mathrm{Hb} \times 1.31 \times \mathrm{SaO}_{2}+0.0031 \times \mathrm{PaO}_{2}$

where $\mathrm{Hb}$ is the haemoglobin concentration $(\mathrm{g} / \mathrm{dL}), 1.31$ is the oxygen-carrying capacity of haemoglobin $\left(\mathrm{mL} / \mathrm{g}\right.$ ) (Larimer, 1959), $\mathrm{Sc}^{\prime} \mathrm{O}_{2}$ is the pulmonary endcapillary oxygen saturation, 0.0031 is the solubility coefficient of oxygen in porcine plasma and $\mathrm{Pc}^{\prime} \mathrm{O}_{2}$ is the pulmonary end capillary partial pressure of oxygen $(\mathrm{mmHg}$ )

Pulmonary end-capillary partial pressure of oxygen was assumed to be equal to $\mathrm{PAO}_{2}$ (alveolar partial pressure of oxygen); for $\mathrm{PAO}_{2}>100 \mathrm{mmHg}$, pulmonary end capillary oxygen saturation was assumed to be $100 \%$ (i.e. 1 ), whereas for $\mathrm{PAO}_{2}$ $\leq 100 \mathrm{mmHg}$, pulmonary end capillary oxygen saturation was calculated from the actual $\mathrm{PAO}_{2}$ via the same method. $\mathrm{FiO}_{2}$ was always assumed to be 0.21 because pigs were breathing room air.

\section{Recovery from anaesthesia}

At T30, pigs were moved to a recovery box to observe recovery from anaesthesia; pigs in the KDMat subgroup received $0.2 \mathrm{mg} / \mathrm{kg}$ atipamezole IM. Times between injection of anaesthetic drugs and the first head movements, sternal recumbency and standing/walking were recorded. Times between atipamezole administration

\footnotetext{
2 See: http://www.randomizer.org (accessed 28 December 2014).
} 
and the first head movements, sternal recumbency and standing/walking were also recorded in the KDMat subgroup. Quality of recovery was assessed using a scoring system from 1 (excellent) to 4 (poor; see Appendix: Supplementary Table S3). Any side effects noted during the procedure and during the following $24 \mathrm{~h}$ were recorded.

\section{Statistical analysis}

Data were tested for normal distribution with the Kolmogorov-Smirnov test, and the means, standard deviations (SDs) and ranges (parametric data: physiological, blood gas and haematological parameters) or median values and ranges (nonparametric data: induction, anaesthesia and recovery scores) were calculated. Parametric physiological data were compared among study times (T0, T10, T20 and T30) and groups using one-way analysis of variance (ANOVA) for repeated measures, while non-parametric data were compared using the Kruskal-Wallis test, followed by Dunn's test (significant at $P<0.05$, MedCalc Software).

\section{Results}

The study was completed without any major complication in all pigs. Two pigs were excluded from the study; one case in the KDM group was excluded because of a non-adequate induction (score 3-4) and one case in the TZM group was excluded because of inadequate anaesthesia (score 5-6). The first signs of sedation after injection of drugs were observed significantly earlier in the TZM group $(47.2 \pm 25.3 \mathrm{~s})$ than the KDM group $(91.5 \pm 37.4 \mathrm{~s} ; P<0.01)$. Sternal and lateral recumbency were achieved earlier in the TZM group (76.3 $\pm 36.5 \mathrm{~s}$ and $132.1 \pm 30.5 \mathrm{~s}$, respectively) than the KDM group ( $149.1 \pm 58.7 \mathrm{~s}$ and $249.2 \pm 84.0$ s, respectively; $P<0.01)$. The median induction scores were similar in both groups (KDM score 1 , range $1-3$; TZM score 1 , range $1-1 ; P=0.15$ ).

The mean time required to approach the animal after injection was significantly shorter in the TZM group (3.08 $\pm 1.15 \mathrm{~min})$ than the KDM group $(7.3 \pm 3.3 \mathrm{~min} ; P<0.01)$.

The mean values of $\mathrm{HR}, \mathrm{RR}, \mathrm{SAP}, \mathrm{DAP}, \mathrm{MAP}, \mathrm{SpO}_{2}$ and $\mathrm{T}$, and the median anaesthesia scores, are presented in Table 1 . The mean values of $\mathrm{T}$ and $\mathrm{SpO}_{2}$ were lower $(P=0.004)$ in the TZM group than the KDM from T10 to T30.

The mean values of $\mathrm{pH}, \mathrm{PaO}_{2}, \mathrm{PaCO}_{2}, \mathrm{SaO}_{2}, \mathrm{P}(\mathrm{A-a}) \mathrm{O}_{2}$, Fshunt, $\mathrm{PaO}_{2}: \mathrm{FiO}_{2}, \mathrm{tHb}, \mathrm{HCO}_{3}{ }^{-}, \mathrm{BE}$, glucose, $\mathrm{TCO}_{2}, \mathrm{Hct}, \mathrm{Na}^{+}, \mathrm{K}^{+}$and $\mathrm{Ca}^{2+}$ are shown in Table 2. The $\mathrm{PaO}_{2}(P<0.01), \mathrm{SaO}_{2}(P<0.01)$ and $\mathrm{PaO}_{2}: \mathrm{FiO}_{2}$ $(P<0.01)$ were lower and the $\mathrm{P}_{(\mathrm{A}-\mathrm{a})} \mathrm{O}_{2}(P<0.01)$ and Fshunt $(P<0.01)$ were higher in the TZM group than the KDM group. Animals did not show any evident motor reaction during the biopsies under either protocol.

Times from drug injection to first head movements $(P<0.01)$, sternal recumbency $(P<0.01)$ and standing/walking (deambulation) $(P<0.01)$ were significantly shorter in the KDM group $(45.1 \pm 10.5$, $48.4 \pm 12.6$ and $54.4 \pm 17.8 \mathrm{~min}$, respectively) than the TZM group (57.8 $\pm 11.4,93.1 \pm 14.2$ and $165.7 \pm 56.6 \mathrm{~min}$, respectively). Pigs that received atipamezole during recovery (KDMat subgroup) had significantly shorter times for first head movement, sternal recumbency

Table 1

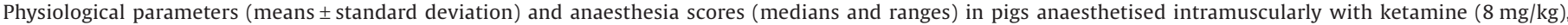

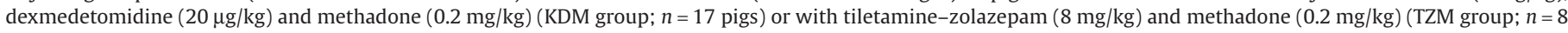
pigs).

\begin{tabular}{|c|c|c|c|c|c|}
\hline \multirow[t]{2}{*}{ Parameters } & \multirow[t]{2}{*}{ Groups } & \multicolumn{4}{|c|}{ Time points in the study } \\
\hline & & T0 & $\mathrm{T} 10$ & T20 & T30 \\
\hline \multirow[t]{2}{*}{ HR } & KDM & $101.2 \pm 12.1$ & $94.6 \pm 14.2$ & $86.0 \pm 14.8$ & $81.0 \pm 14.2$ \\
\hline & TZM & $117.2 \pm 22.7$ & $95.0 \pm 26.6$ & $85.2 \pm 23.3$ & $77.8 \pm 17.1$ \\
\hline \multirow[t]{2}{*}{$\mathrm{RR}$} & KDM & $41.3 \pm 15.5$ & $44.0 \pm 15.0$ & $43.6 \pm 20.0$ & $49.2 \pm 16.5$ \\
\hline & TZM & $28.3 \pm 13.9$ & $31.4 \pm 13.9$ & $33.2 \pm 15.9$ & $34.2 \pm 17.7$ \\
\hline \multirow[t]{2}{*}{ SAP } & KDM & $158.0 \pm 31.3$ & $149.2 \pm 19.9$ & $144.3 \pm 18.0$ & $143.6 \pm 23.8$ \\
\hline & TZM & $147.3 \pm 22.8$ & $148.7 \pm 4.5$ & $157.5 \pm 31.4$ & $141.0 \pm 12.1$ \\
\hline \multirow[t]{2}{*}{ MAP } & KDM & $114.4 \pm 22.0$ & $111.5 \pm 17.4$ & $111.0 \pm 18.8$ & $115.0 \pm 19.7$ \\
\hline & TZM & $112.7 \pm 16.6$ & $110.3 \pm 20.3$ & $124.7 \pm 37.8$ & $118.3 \pm 14.4$ \\
\hline \multirow[t]{2}{*}{ DAP } & KDM & $91.8 \pm 23.9$ & $92.5 \pm 15.1$ & $90.4 \pm 18.8$ & $91.3 \pm 21.3$ \\
\hline & TZM & $86.3 \pm 16.6$ & $81.1 \pm 21.6$ & $106.7 \pm 42.7$ & $98.0 \pm 20.1$ \\
\hline \multirow[t]{2}{*}{$\mathrm{SpO}_{2}$} & KDM & $92.3 \pm 3.9$ & $92.9 \pm 2.2$ & $94.3 \pm 2.5$ & $95.7 \pm 3.2$ \\
\hline & TZM & $89.6 \pm 2.8$ & $89.8 \pm 2.7^{*}$ & $90.5 \pm 3.6^{*}$ & $90.6 \pm 3.6^{*}$ \\
\hline \multirow[t]{2}{*}{$\mathrm{T}$} & KDM & $38.2 \pm 0.7$ & $38.0 \pm 0.6$ & $37.7 \pm 0.6$ & $37.3 \pm 0.8$ \\
\hline & TZM & $37.0 \pm 0.7$ & $36.6 \pm 0.94^{*}$ & $36.3 \pm 0.8^{*}$ & $36.1 \pm 0.6^{*}$ \\
\hline \multirow[t]{2}{*}{ AS } & KDM & $2(2-6)$ & $2(2-4)$ & $3(2-5)$ & $3(2-5)$ \\
\hline & TZM & $2(2-3)$ & $2(2-3)$ & $2(2-5)$ & $2(2-5)$ \\
\hline
\end{tabular}

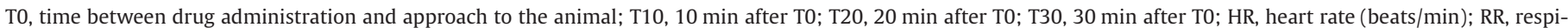

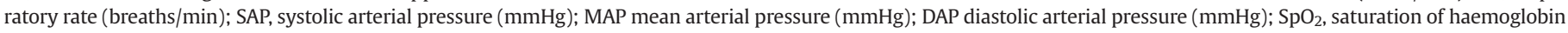
with oxygen (\%); T, rectal temperature $\left({ }^{\circ} \mathrm{C}\right)$; AS, anaesthesia score (median and range).

* Significant statistical differences between groups $(P<0.05)$.

Table 2

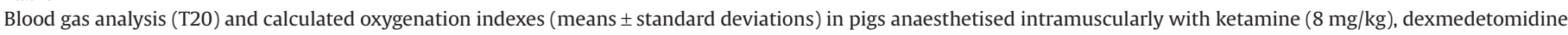
$(20 \mu \mathrm{g} / \mathrm{kg})$ and methadone $(0.2 \mathrm{mg} / \mathrm{kg})$ (KDM group; $n=17$ pigs) or with tiletamine-zolazepam ( $8 \mathrm{mg} / \mathrm{kg})$ and methadone $(0.2 \mathrm{mg} / \mathrm{kg})$ in TZM group ( $8 \mathrm{pigs})$.

\begin{tabular}{|c|c|c|c|c|c|c|c|c|}
\hline \multirow[t]{2}{*}{ Groups } & \multicolumn{8}{|c|}{ Parameters } \\
\hline & $\mathrm{pH}$ & $\mathrm{PaO}_{2}$ & $\mathrm{PaCO}_{2}$ & $\mathrm{SaO}_{2}$ & $\mathrm{P}_{(\mathrm{A}-\mathrm{a})} \mathrm{O}_{2}$ & Fshunt & $\mathrm{PaO}_{2}: \mathrm{FiO}_{2}$ & $\mathrm{tHb}$ \\
\hline KDM & $7.4 \pm 0.0$ & $80.4 \pm 5.9$ & $48.2 \pm 2.8$ & $95.7 \pm 1.0$ & $20.7 \pm 7.4$ & $13.4 \pm 3.2$ & $380.4 \pm 25.6$ & $9.8 \pm 0.3$ \\
\hline \multirow[t]{2}{*}{ TZM } & $7.4 \pm 0.0$ & $68.7 \pm 4.1^{*}$ & $49.8 \pm 2.1$ & $93.4 \pm 1.4^{*}$ & $31.4 \pm 3.8^{*}$ & $24.0 \pm 11.8^{*}$ & $327.2 \pm 19.9^{*}$ & $13.51 \pm 9.0$ \\
\hline & $\mathrm{HCO}_{3}^{-}$ & $\mathrm{BE}$ & Glucose & $\mathrm{TCO}_{2}$ & Hct & $\mathrm{Na}^{+}$ & $\mathrm{K}^{+}$ & $\mathrm{Ca}^{2+}$ \\
\hline KDM & $33.5 \pm 3.3$ & $9.3 \pm 3.9$ & $111.8 \pm 20.0$ & $35.6 \pm 3.9$ & $28.9 \pm 1.0$ & $140.9 \pm 1.78$ & $3.7 \pm 0.1$ & $1.3 \pm 0.0$ \\
\hline TZM & $32.9 \pm 2.1$ & $7.1 \pm 2.4$ & $95.8 \pm 12.0$ & $34.2 \pm 2.2$ & $29.3 \pm 1.6$ & $141.0 \pm 0.6$ & $3.83 \pm 0.1$ & $1.35 \pm 0.0$ \\
\hline
\end{tabular}

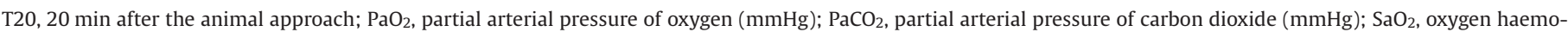

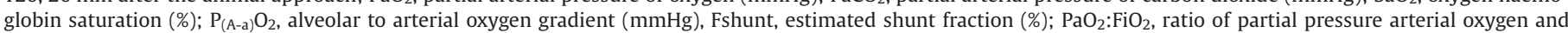

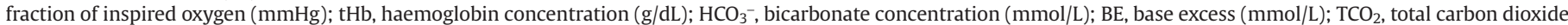
content (vol\%); Hct, haematocrit (\%).

* Statistical differences between groups at given time points $(P<0.05)$. 
and standing/walking (39.1 $\pm 6.0,40.2 \pm 6.2$ and $42.5 \pm 6.3 \mathrm{~min})$ compared with the TZM group and KDMnoat subgroup (51.7 \pm 9.6 , $58.6 \pm 8.9$ and $68.8 \pm 14.9 \mathrm{~min}$, respectively). In the KDMat, after atipamezole administration ( $37.5 \pm 6.0 \mathrm{~min}$ ), the mean time to first head movement was $90.3 \pm 64.7 \mathrm{~s}$, to sternal recumbency was $157.4 \pm 86.3 \mathrm{~s}$ and to standing/walking was $4.7 \pm 2.6 \mathrm{~min}$. The median recovery score was higher $(P<0.01)$ in the TZM group (median 3 , range 2-4) than in the KDMnoat (median 2, range 1-2) and KDMat (median 1, range 1-3) subgroups. The quality of recovery was similar between the KDMnoat and KDMat subgroups.

\section{Discussion}

The results of this study suggest that the combinations of tiletamine-zolazepam-methadone and ketamine-dexmedetomidinemethadone, with or without atipamezole, are both suitable protocols for providing short-term anaesthesia for minor surgical procedures in pigs. The TZM combination provided shorter induction times, but also caused a greater derangement of gas exchange and poorer recovery quality than the KDM protocol. Administration of atipamezole at the end of the procedure, in animals receiving dexmedetomidine, shortened the recovery time.

The time for induction of anaesthesia may play a critical role for the quality of the anaesthesia in domestic pigs, since they are 'easy to stress' and become restless if the lapse of time between injection of intramuscular drugs and induction of anaesthesia is too long (Henrikson et al., 1995). The increase in sympathetic tone that occurs in this phase may interfere with the onset of the sedative effect of the drugs administered (Fournier et al., 1995; Sweitzer et al., 1997; Caulkett and Arnemo, 2007). The protocols tested in this study provided reasonable (within $5 \mathrm{~min}$ ) induction times (Lu et al., 2010; Lee and Kim, 2012), but the TZM combination was superior, since it produced lateral recumbency in almost half the time compared to the KDM group. As a consequence, the time to approach the animal was shorter, making this combination more suitable for fractious animals.

The quality of induction of anaesthesia was good in both groups, with the animals making from one to three attempts to lie in sternal or lateral recumbency, with or without mild signs of excitement (induction scores 1 or 2; see Appendix: Supplementary Table S1). In one case, the KDM protocol failed to produce adequate induction and an extra dose of ketamine was required in order to continue with the procedure. Misplacement of the needle or a different individual sensitivity to the drug could have been responsible for an abnormal effect in this animal.

The depth of anaesthesia was adequate (anaesthesia scores 4-5; see Appendix: Supplementary Table S2) during the period of observation in both groups. In all pigs, skin and mucosal biopsies were collected without any complications. Experimental subjects did not show any sign of nociception, indicating that the combinations of tiletamine and methadone in the TZM group, and of ketamine, dexmedetomidine and methadone in the KDM group, provided an adequate level of analgesia for cutaneous or mucosal biopsy.

Many factors are responsible for decreases in body temperature during general anaesthesia (Díaz and Becker, 2010). Agitation and stress during induction of anaesthesia may contribute to the development of hyperthermia (Parrott and Lloyd, 1995). In our study, pigs in the TZM group had a lower rectal temperature than pigs in the KDM group from T10 to T30. The main factors that could have contributed to the better maintenance of body temperature in the KDM group are the longer induction time (which could have increased the body temperature of the animals) and the peripheral vasoconstriction induced by dexmedetomidine, which reduces peripheral heat loss (Sinclair, 2003).

Blood pressure was high (mean MAP $>110 \mathrm{mmHg}$ ) with both protocols from T0 to T30. Dissociative anaesthetic drugs cause central activation of the sympathetic nervous systemic, an increase in blood pressure and cardiac inotropism (Wong and Jenkins, 1974). $\alpha 2$ agonist drugs induce a transitory initial phase of peripheral vasoconstriction that usually results in systemic hypertension (Sinclair, 2003). We speculate that the effects of the dissociative drugs were mainly responsible for the hypertension observed in our pigs. Moreover, it seems that dexmedetomidine did not have an additive effect on haemodynamic conditions, since there was no significant difference in blood pressures between the KDM and TZM groups.

$\mathrm{PaO}_{2}: \mathrm{FiO}_{2}$ and Fshunt are two common indicators of venous admixture (Araos et al., 2012). There was a moderate degree of impairment of oxygenation and ventilation with both protocols, but the impairment was greater in the TZM group. $\mathrm{PaO}_{2}$ and the $\mathrm{PaO}_{2}: \mathrm{FiO}_{2}$ were lower than physiological ranges $(90-100 \mathrm{mmHg}$ and 400-500 mmHg, respectively) in room air (Haskins et al., 2005; McDonnel and Kerr, 2007), particularly in the TZM group, where most pigs had $\mathrm{PaO}_{2}$ values $<70 \mathrm{mmHg}, \mathrm{PaO}_{2}: \mathrm{FiO}_{2}<350 \mathrm{mmHg}$ and Fshunt values higher than those in the KDM group. We assume that the TZM combination induced a greater impairment of gas exchange due to a greater amount of intrapulmonary shunt fraction. The $\mathrm{SaO}_{2}$ was lower in TZM than the KDM group, but it was never $<90 \%$ in both protocols. However, it is strongly recommended to provide oxygen supplementation (e.g. flow-by, nasal cannula, face mask) to compensate for the mild derangement of lung function induced by these protocols (Haskins, 1992).

Ketamine and, to a greater extent, tiletamine, as well as dexmedetomidine, increase the pressure of the pulmonary circulation (Lagutchik et al., 1991; Sano et al., 2010; Pypendop et al., 2011). Pulmonary hypertension may also have influenced gas exchange in our animals, but we did not measure this parameter. In the TZM and KDM groups, a moderate degree of hypoventilation was observed, indicated by increased values of $\mathrm{PaCO}_{2}(>45 \mathrm{mmHg})$ and respiratory rates ( $>30$ breaths/min). Dissociative anaesthetic drugs, as well as $\alpha 2$ agonists, have minor respiratory effects (Sinclair, 2003; Craven, 2007); the hypoventilation observed in this study might be attributed to the effects of methadone.

The results of this study demonstrated that the TZM protocol was associated with longer recovery times than the KDM protocol; moreover, administration of atipamezole at the end of the surgical procedure further shortened the recovery in the KDMat protocol. Atipamezole did not affect the recovery score in the KDMat subgroup compared to the KDMnoat subgroup. This result could be related to the low number of animals and/or because atipamezole was administered at a time (30-40 min after dexmedetomidine administration) when the sedative effects of the $\alpha 2$ agonist had almost disappeared. Times for sternal recumbency and standing/walking were almost doubled in the TZM group compared with the KDM group, suggesting that, despite a similar time of immobilisation, the TZM protocol produced a prolonged recovery. Moreover, the quality of recovery was worse in the TZM group, with the pigs making numerous attempts and frequent transitions from lateral to sternal recumbency and severe ataxia. These findings may be related to the longer duration of action of tiletamine and zolazepam compared to ketamine (Kumar et al., 2006; Lin, 2007).

\section{Conclusions}

The results of this study suggest that TZM and KDM produce adequate anaesthesia for minor surgical procedures in domestic pigs for about $30 \mathrm{~min}$. However, the KDM protocol appeared to be superior to the TZM protocol, which, although producing faster immobilisation, resulted in a more prolonged and poorer quality of recovery, and a greater impairment of lung function. In animals treated with the KDM protocol, administration of atipamezole 30-40 min after anaesthetic drugs shortened the recovery time, but did not affect the quality of recovery. 


\section{Conflict of interest statement}

None of the authors has any financial or personal relationship that could inappropriately influence or bias the content of the paper.

\section{Appendix: Supplementary material}

Supplementary data to this article can be found online at doi:10.1016/j.tvjl.2015.05.011.

\section{References}

Araos, J.D., Larenza, M.P., Boston, R.C., De Monte, V., De Marzo, C., Grasso, S., Haskins S.C., Crovace, A., Staffieri, F., 2012. Use of the oxygen content-based index, Fshunt as an indicator of pulmonary venous admixture at various inspired oxygen fractions in anesthetized sheep. American Journal of Veterinary Research 73 2013-2020.

Boschert, K., Flecknell, P.A., Fosse, R.T., Framstad, T., Ganter, M., Sjøstrand, U., Stevens, J., Thurman, J., 1996. Ketamine and its use in the pig. Recommendations of the Consensus Meeting on Ketamine Anaesthesia in Pigs, Bergen 1994. Ketamine Consensus Working Group. Laboratory Animals 30, 209-219.

Brodbelt, D.C., Taylor, P.M., 1999. Comparison of two combinations of sedatives before anaesthetising pigs with halothane and nitrous oxide. Veterinary Record 145 283-287.

Caulkett, N.A., Arnemo, J.M., 2007. Chemical immobilization of free-ranging terrestrial mammals. In: Tranquilli, W.J., Thurmon, J.C., Grimm, K.A. (Eds.), Lumb \& Jones' Veterinary Anaesthesia and Analgesia, Fourth Ed. Blackwell Publishing, Ames, IA, USA, pp. 806-831.

Cohen, I.L., Sheikh, F.M., Perkins, R.J., Feustel, P.J., Foster, E.D., 1995. Effect of hemorrhagic shock and reperfusion on the respiratory quotient in swine. Critical Care Medicine 23, 545-552.

Craven, R., 2007. Ketamine. Anaesthesia 62, 48-53.

Díaz, M. Becker, D.E. 2010. Thermoregulation: Physiological and clinical considerations during sedation and general anaesthesia. Anaesthesia Progress $57,25-32$.

Ebert, B., Andersen, S., Krogsgaard-Larsen, P., 1995. Ketobemidone, methadone and pethidine are non-competitive N-methyl-D-aspartate (NMDA) antagonists in the rat cortex and spinal cord. Neuroscience Letters 187, 165-168.

Fournier, P., Fournier-Chambrillon, C., Maillard, D., Klein, F., 1995. Zoletil immobilization of wild boar (Sus scrofa L.). Journal of Mountain Ecology 3, 134-136.

Grasso, S., Stripoli, T., Sacchi, M., Trerotoli, P., Staffieri, F., Franchini, D., De Monte, V., Valentini, V., Pugliese, P., Crovace, A., et al., 2009. Inhomogeneity of lung parenchyma during the open lung strategy: A computed tomography scan study. American Journal of Respiratory and Critical Care Medicine 180, 415-423.

Haskins, S., Pascoe, P.J., Ilkiw, J.E., Fudge, J., Hopper, K., Aldrich, J., 2005. Reference cardiopulmonary values in normal dogs. Comparative Medicine 55, 156-161.

Haskins, S.C., 1992. Monitoring the anesthetized patient. Veterinary Clinics of North America: Small Animal Practice 22, 425-431.

Hastings, A.B., White, F.C., Sanders, T.M., Bloor, C.M., 1982. Comparative physiological responses to exercise stress. Journal of Applied Physiology 52, 1077-1083.

Heinonen, M.L., Raekallio, M.R., Oliviero, C., Ahokas, S., Peltoniemi, O.A., 2009. Comparison of azaperone-detomidine-butorphanol-ketamine and azaperonetiletamine -zolazepam for anaesthesia in piglets. Veterinary Anaesthesia and Analgesia 36, 151-157.

Henrikson, H., Jensen-Waern, M., Nyman, G., 1995. Anaesthetics for general anaesthesia in growing pigs. Acta Veterinaria Scandinavica 36, 401-411.

Hermansen, K., Pedersen, L.E., Olesen, H.O., 1986. The analgesic effect of buprenorphine, etorphine and pethidine in the pig: A randomized double blind cross-over study. Acta Pharmacologica et Toxicologica 59, 27-35.

Jordan, J.E., Mays, J.J., Shelton, J.E., Bryant, A.K., Lane, M.R., Morykwas, M.J., Argenta, L.C., 2014. Mechanical tissue resuscitation protects against myocardial ischemiareperfusion injury. Journal of Cardiac Surgery 29, 116-123.

Kumar, A., Mann, H.J., Remmel, R.P., 2006. Pharmacokinetics of tiletamine and zolazepam (Telazol) in anesthetized pigs. Journal of Veterinary Pharmacology and Therapeutics 29, 587-589.

Lagutchik, M.S., Januszkiewicz, A.J., Dodd, K.T., Martin, D.G., 1991. Cardiopulmonary effects of a tiletamine-zolazepam combination in sheep. American Journal of Veterinary Research 52, 1441-1447.

Lamont, L.A., Mathews, K.A., 2007. Opioids, nonsteroidal antiinflammatories, and analgesic Adjuvants. In: Tranquilli, W.J., Thurmon, J.C., Grimm, K.A. (Eds.), Lumb \& Jones' Veterinary Anaesthesia and Analgesia, Fourth Ed. Blackwell Publishing, Ames, IA, USA, pp. 241-271.

Laricchiuta, P., De Monte, V., Campolo, M., Grano, F., Iarussi, F., Crovace, A., Staffieri, F. 2012. Evaluation of a butorphanol, detomidine, and midazolam combination for immobilization of captive Nile Lechwe antelopes (Kobus magaceros). Journal of Wildlife Diseases 48, 739-746.
Larimer, J.L., 1959. Hemoglobin concentration and oxygen capacity of mammalian blood. Journal of the Elisha Mitchell Scientific Society 75, 174-177.

Lee, J.Y., Kim, M.C., 2012. Anaesthesia of growing pigs with tiletamine-zolazepam and reversal with flumazenil. Journal of Veterinary Medical Science 74, 335339.

Lee, J.Y., Jee, H.C., Jeong, S.M., Park, C.S., Kim, M.C., 2010. Comparison of anaesthetic and cardiorespiratory effects of xylazine or medetomidine in combination with tiletamine/zolazepam in pigs. Veterinary Record 167, 245-249.

Lin, H.C., 2007. Dissociative anesthetics. In: Tranquilli, W.J., Thurmon, J.C., Grimm, K.A. (Eds.), Lumb \& Jones' Veterinary Anaesthesia and Analgesia, Fourth Ed. Blackwell Publishing, Ames, IA, USA, pp. 301-353.

Lin, H.C., Thurmon, J.C., Benson, G.J., Tranquilli, W.J., 1993. Telazol - a review of its pharmacology and use in veterinary medicine. Journal of Veterinary Pharmacology and Therapeutics 16, 383-418.

Linkenhoker, J.R., Burkholder, T.H., Linton, C.G., Walden, A., Abusakran-Monday, K.A., Rosero, A.P., Foltz, C.J., 2010. Effective and safe anesthesia for Yorkshire and Yucatan swine with and without cardiovascular injury and intervention. Journal of the American Association for Laboratory Animal Science 49, 344-351.

Lu, D.Z., Fan, H.G., Wang, H.B., Hu, K., Zhang, J.T., Yu, S.M., 2010. Effect of the addition of tramadol to a combination of tiletamine-zolazepam and xylazine for anaesthesia of miniature pigs. Veterinary Record 167, 489-492.

Mackenzie, J.G., 1963. A nomogram for b.t.p.s.-volume corrections in pulmonary ventilation tests. Thorax $18,358-360$.

McDonnel, W., Kerr, C.L., 2007. Respiratory system. In: Tranquilli, W.J., Thurmon, J.C. Grimm, K.A. (Eds.), Lumb \& Jones' Veterinary Anaesthesia and Analgesia, Fourth Ed. Blackwell Publishing, Ames, IA, USA, pp. 117-151.

Nishimura, R., Sakaguchi, M., Mochizuki, M., Sasaki, N., Takahashi, H., Tamura, H., Takeuchi, A., 1992. A balanced anaesthesia with a combination of xylazine, ketamine and butorphanol and its antagonism by yohimbine in pigs. Journal of Veterinary Medical Science 54, 615-620.

Nunes, S., Berg, L., Raittinen, L.P., Ahonen, H., Laranne, J., Lindgren, L., Parviainen, I., Ruokonen, E., Tenhunen, J., 2007. Deep sedation with dexmedetomidine in a porcine model does not compromise the viability of free microvascular flap as depicted by microdialysis and tissue oxygen tension. Anaesthesia and Analgesia 105, 66-72.

Parrott, R.F., Lloyd, D.M., 1995. Restraint, but not frustration, induces prostaglandinmediated hyperthermia in pigs. Physiology and Behavior 57, 1051-1055.

Pypendop, B.H., Barter, L.S., Stanley, S.D., Ilkiw, J.E., 2011. Hemodynamic effects of dexmedetomidine in isoflurane-anesthetized cats. Veterinary Anaesthesia and Analgesia 38, 555-567.

Reves, J.G., Glass, P.S.A., Lubarsky, D.A., McEvoy, M.D., 2005. Miller, R.D. (Ed.), Miller's Anesthesia, Sixth Ed. Elsevier Churchill Livingstone, Philadelphia, PA, USA, pp. 317-378.

Sakaguchi, M., Nishimura, R., Sasaki, N., Ishiguro, T., Tamura, H., Takeuchi, A., 1992. Enhancing effect of butorphanol on medetomidine-induced sedation in pigs. Journal of Veterinary Medicine Science 54, 1183-1185.

Sakaguchi, M., Nishimura, R., Sasaki, N., Ishiguro, T., Tamura, H., Takeuchi, A., 1995. Chemical restraint by medetomidine-ketamine and its cardiopulmonary effects in pigs. Zentralblatt für Veterinärmedizin. Reihe A 42, 293-299.

Sakaguchi, M., Nishimura, R., Sasaki, N., Ishiguro, T., Tamura, H., Takeuchi, A., 1996 Anaesthesia induced in pigs by use of a combination of medetomidine, butorphanol, and ketamine and its reversal by administration of atipamezole. American Journal of Veterinary Research 57, 529-534.

Sano, H., Doi, M., Mimuro, S., Yu, S., Kurita, T., Sato, S., 2010. Evaluation of the hypnotic and hemodynamic effects of dexmedetomidine on propofol-sedated swine. Experimental Animals 59, 199-205.

Santos González, M., Bertrán de Lis, B.T., Tendillo Cortijo, FJ., 2013. Effects of intramuscular alfaxalone alone or in combination with diazepam in swine. Veterinary Anaesthesia and Analgesia 40, 399-402.

Santos, M., Bertrán de Lis, B.T., Tendillo, F.J., 2015. Effects of intramuscular dexmedetomidine in combination with ketamine or alfaxalone in swine. Veterinary Anaesthesia and Analgesia doi:10.1111/vaa.12259.

Sinclair, M.D., 2003. A review of the physiological effects of alpha2-agonists related to the clinical use of medetomidine in small animal practice. Canadian Veterinary Journal 44, 885-897.

Staffieri, F., Stripoli, T., De Monte, V., Crovace, A., Sacchi, M., De Michele, M., Trerotoli, P., Terragni, P., Ranieri, V.M., Grasso, S., 2012. Physiological effects of an open lung ventilatory strategy titrated on elastance-derived end-inspiratory transpulmonary pressure: Study in a pig model. Critical Care Medicine 40, 2124-2131.

Stenberg, D., 1986. The role of alpha-adrenoceptors in the regulation of vigilance and pain. Acta Veterinaria Scandinavica. Supplementum 82, 29-34.

Sweitzer, R.A., Ghneim, G.S., Gardner, I.A., Van Vuren, D., Gonzales, B.J., Boyce, W.M.J., 1997. Immobilization and physiological parameters associated with chemical restraint of wild pigs with Telazol and xylazine hydrochloride. Journal of Wildlife Diseases 33, 198-205.

Swindle, M.M., Smith, A.C., Laber-Laird, K., Dungan, L., 1994. Swine in biomedical research: Management and models. ILAR Journal 36, 1-5.

Wong, D.H., Jenkins, L.C., 1974. An experimental study of the mechanism of action of ketamine on the central nervous system. Canadian Anaesthetists' Society Journal 21, 57-67. 